\title{
LUGARES DE ENUNCIAÇÃO E DISCURSO
}

\section{Mónica G. Zoppi Fontana (UNICAMP)}

Gostaria de começar este trabalho' fazendo uma referência autobiográfica. O título de um trabalho publicado na Argentina (1992) incluía como subtítulo EL PODER DE ENUNCIAR. Observando a distância (temporal e teórica) esse subtítulo, percebo e faço trabalhar a ambigüidade do sintagma $O$ poder de enunciar, na sua dupla leitura como possibilidade de dizer/eficácia do dizer. Em um texto mais recente (o livro Cidadãos modernos. Discurso e representação política, 1997), volto a encontrar essa antiga inquietação, agora já nomeada como lugar de enunciação na análise que desenvolvo sobre o discurso da transição na Argentina e, mais especificamente, sobre o funcionamento da figura do porta-voz. Nesse texto, cujo objetivo é trabalhar o fundamento discursivo da representação política, considero a figura do porta-voz como um lugar de enunciação e, enquanto tal, como uma das formas históricas do sujeito de enunciação (Guilhaumou, 1989). Na análise apresentada nesse meu livro, gostaria de destacar, em primeiro lugar, a relação estabelecida entre certos funcionamentos enunciativos e o processo de configuração (e de legitimação) das relações de representação política em um espaço institucional (no caso, a presidência da Nação). Em segundo lugar, a afirmação teórica da determinação dos funcionamentos enunciativos pelo interdiscurso, o que leva a estabelecer uma relação necessária de um lugar de enunciação (a figura do porta-voz, p.e.) com as posições de sujeito que o definem e das quais é uma dimensão constitutiva. Em terceiro lugar, a decisão metodológica de descrever um lugar de enunciação a partir de funcionamentos discursivos tais como metáfora, metonímia e dêixis discursiva, o que supõe não reduzir essa descrição ao jogo polifônico das figuras enunciativas (locutor, enunciador).

Apresentado na mesa redonda DISCURSO E SUJEITO, coordenada por Maria Virgínia Borges Amaral, no II CONGRESSO INTERNACIONAL DA ABRALIN, realizado em Fortaleza, em março de 2001. Agradeço ao público seus comentários e sugestões, que muito contribuíram na redação da versão final do texto. 
Retomando essas questões, e especificamente as elaborações sobre a noção de lugar de enunciação, neste trabalho gostaria de desenvolver algumas considerações que são fruto de reflexão desenvolvida em conjunto com alunos e orientandos ${ }^{2}$. A problemática que abordamos através da noção de lugar de enunciação poderia resumir-se como uma reflexão sobre a divisão social do direito de enunciar e a eficácia dessa divisão e da linguagem em termos da produção de efeitos de legitimidade, verdade, credibilidade, autoria, circulação, identificação, na sociedade. Posto dessa maneira, o tema já foi objeto de numerosos estudos, principalmente de orientação sociológica, etnográfica e pragmática. Minha reflexão se inscreve em uma posição teórica que se define em relação à Teoria da Análise do Discurso (doravante AD), filiada a M. Pêcheux. Gostaria também de frisar que as colocações que se seguem apresentam o estado atual de uma reflexão que está em andamento, o que justifica o caráter incompleto e provisório de algumas afirmações.

Em seu texto Análise automática do discurso de 1969 (doravante AAD69), Pêcheux, ao explicitar os elementos que constituem as condições de produção do discurso, afirma:

A e B designam lugares determinados na estrutura de uma formação social, lugares dos quais a sociologia pode descrever o feixe de traços objetivos caracteristicos: assim, p.e., no interior da esfera da produção econômica, os lugares do "patrão" (diretor, chefe de empresa, etc.), do funcionário de repartiçäo, do contramestre, do operário, são marcados por propriedades diferenciais determináveis. Nossa hipótese é a de que esses lugares estäo representados nos processos discursivos em que são colocados em jogo. Entretanto, seria ingênuo supor que o lugar como feixe de traços objetivos funciona como tal no interior do processo discursivo; ele se encontra ai representado, i.e., presente, mas transformado [...] Se assim ocorre, existem nos mecanismos de qualquer formação social regras de projeção, que estabelecem as relaçöes entre as situaçöes (objetivamente definiveis) e as posições (representações dessas situações) (Pêcheux, 1969:82).

Por isso, quero fazer pública minha divida e citar seu nomes como interdiscurso dessa minha prática de escrita. Sou grata a Neuza Zattar, Ana Josefina Ferrari, Vera Regina Martins e Silva, José Guillermo Milán Ramos, Águeda Cruz Borges, Lucimar Ferreira, Gislaine Pinto Ferreira, Lúcia Insarraulde, Josefa Gomes Farias, Mônica Oliveira Santos, Carmen Agustini e M. Virgínia Borges Amaral. 
Algumas páginas antes dessa citação, no mesmo texto, ainda descrevendo as condições de produção do discurso, Pêcheux ilustra com o exemplo de um discurso pronunciado por um deputado e afirma:

O que diz, o que anuncia, promete ou denuncia não tem o mesmo estatuto conforme o lugar que ele ocupa; a mesma declaração pode ser uma arma temivel ou uma comédia ridicula segundo a posição do orador e do que ele representa, em relação ao que diz [...] Podemos citar aqui o conceito de "enunciado performativo" introduzido por J.L. Austin, para sublinhar a relação necessária entre um discurso e seu lugar em um mecanismo institucional extralingüistico (Pêcheux, 1969:77).

Queremos destacar neś́as citações, por um lado, a consideração dos efeitos produzidos por uma enunciação em relação ao lugar a partir do qual ela é proferida, por outro lado, a relação desse lugar com um mecanismo institucional do qual retira sua eficácia.

Essas formulações, que foram revisadas criticamente pelo próprio autor em textos posteriores (Pêcheux, 1975, 1983), encontravam seu fundamento nos procedimentos de construção do corpus adotados na AAD69, que privilegiavam condições de produção estáveis e um conceito de formação discursiva homogênea, fechada sobre si mesma e fortemente ancorada em uma inscrição institucional. Porém, vale a pena destacar que no mesmo texto já se encontram os elementos que bloqueiam uma interpretação pragmática, retórica ou sociológica das $\mathrm{CP}$, ao defini-las como sedimentação de discursos anteriores. Assim, já é possível descobrir nesse texto inicial o germe da noção de interdiscurso, que será o carro-chefe da teoria no seu desenvolvimento posterior.

Por oposição à tese fenomenológica que colocaria a apreensão perceptiva do referente, do outro e de si mesmo como condição pré-discursiva do discurso, supomos que a percepção é sempre atravessada pelo "já ouvido" e o "já dito", através dos quais se constitui a substância das formações imaginárias enunciadas [...] um estado dado das CP deveria ser compreendido como resultado de processos discursivos sedimentados: vê-se que é pois impossivel definir uma origem das CP (p. 85-87).

Ancorados nessas afirmações, e desconhecendo a ênfase do autor em apontar para o fato de que os lugares se encontram presentes mas transformados por regras de projeção que permitem passar de situações objetivas para posições representadas, alguns autores 
filiados à $\mathrm{AD}$, trabalham a questão dos lugares de enunciação e da eficácia do discurso, pressupondo uma tipologia poucas vezes explicitada de lugares sociais, gêneros discursivos, instituições, comunidades. Tal parece ser o caso de Maingueneau (1990:32), que afirma que a AD prefere formular as instâncias de enunciação em termos de "lugares", visando a enfatizar a preeminencia e a preexistência da topografia social sobre os falantes que ai vêm se inscrever. Embora o autor relativize essa sua afirmação citando J.P. Faye, que observa que os lugares sociais só podem existir através de uma rede de lugares discursivos, os quais se apóiam em uma economia distinta, poucas páginas adiante volta a aparecer a questão de uma topografia social pela noção de comunidade discursiva daqueles que produzem, que fazem com que o discurso circule, que se reuinem em seu nome e nele se reconhecem (idem:54). Assim, Maingueneau pode concluir sustentando que as formações discursivas [...] também se opóem pelo modo de funcionamento dos grupos que thes estão associados (idem:55, grifos meus). Essa oscilação definicional e um certo ecletismo nas filiações teóricas (em um mesmo capítulo recorre a Ducrot, Parret, Flahaut, Foucault, Guilhaumou, Faye, Bourdieu) são efeito, na nossa opinião, da ausência (presente nos seus efeitos) de conceitos trabalhados no quadro do materialismo histórico, principalmente o de interpelação ideológica e forma-sujeito, evitados cuidadosamente ou descartados com pressa.

O meu esforço de teorização neste trabalho (ainda que inicial) se caracteriza como uma tentativa de pensar o conjunto de questões levantadas até aqui através da noção de lugar de enunciação (e sua eficácia ideológica) no quadro teórico da figura da interpelação ideológica, considerando o processo de constituição do sujeito do discurso nas relações de identificação estabelecidas com a formasujeito e as posições de sujeito definidas nas FD que o afetam. Neste sentido, retomo a crítica em que o próprio Pêcheux (1983) realizou a apresentação das condições de produção em AAD69, apontando por um lado a perigosa aproximação que esse texto permitia, apesar das ressalvas já citadas, entre condições de produção e situação concreta de enunciação de um sujeito falante; e, por outro lado, os pressupostos que sustentavam a prática analítica, que estabeleciam na construção do corpus uma relação quase imediata entre condições de produção 
estáveis, formações discursivas homogêneas e discursos identificados a priori pelas suas inscrições institucionais e/ou ideológicas.

Porém, como apontado por Pêcheux na sua análise do desenvolvimento da teoria do discurso, a emergência de novos procedimentos da $A D$ através da desconstrução das maquinárias discursivas (1983:315) afastou, pelo desenvolvimento do conceito de interdiscurso e a descrição dos mecanismos de interpelação ideológica contraditória, a teoria dessa primeira versão que, como já demonstramos, abria espaço para que outros autores definissem o sujeito do discurso a partir de uma "topografia social" de lugares.

Em textos posteriores, Pêcheux (1975) afirma que "os individuos são interpelados ém sujeitos falantes (em sujeitos dos seus discurso) pelas FD que representam 'na linguagem' as formações ideológicas", e acrescenta: "a interpelação do individuo em sujeito do seu discurso se efetua pela identificação (do sujeito) com a FD que o domina (i.e., na qual ele é constituído como sujeito)". Mas adiante, o autor acrescenta que tal identificação ocorre pelo viés da formasujeito. Assim, podemos afirmar com Indursky (2000), de cujo texto nos valemos para fazer esse percurso sumário sobre os processo de constituição do sujeito do discurso, que este "identifica-se com a forma-sujeito, vale dizer, com a FD cujo dizer é por ela organizado".

$\mathrm{O}$ trabalho de Indursky nos é precioso no sentido em que demonstra o trajeto percorrido pela teoria da $\mathrm{AD}$ de uma conceituação de FD como unidade homogênea e fechada sobre si mesma, a uma definição que a considera como unidade dividida, heterogênea em relação a si mesma, constitutivamente afetada pela contradição, delimitada por fronteiras instáveis e em contínuo processo de reconfiguração. A partir dessa caracterização da FD, Indursky conclui no seu trabalho que a forma-sujeito que organiza uma FD é, portanto, necessariamente heterogênea. Citando a autora:

estamos diante de um conjunto de diferentes posições de sujeito, que evidenciam diferentes formas de se relacionar com a ideologia e é esse elenco de posições-sujeito que vai dar conta da forma-sujeito (Indursky, 2000:76).

Para continuar com nossa reflexão, é preciso lembrar que Courtine (1981), que propôs (através da noção de enunciado dividido) considerar as FD como divididas, instáveis e heterogêneas, define (inspirado em Foucault) a FD como domínio de saber e caricteriza a 
forma-sujeito de uma FD como sujeito universal de saber. O autor descreve "o conjunto das diferentes posições de sujeito em uma FD como modalidades particulares de identificação do sujeito da enunciação ao sujeito do saber" (Courtine, apud Indursky, 2000:76).

Neste ponto, interessa trazer para o debate algumas críticas e revisões elaboradas por Courtine \& Marandin (1983). Os autores defendem:

1- o primado do interdiscurso, e aqui recorro à citação desse texto: $O$ interdiscurso não é uma "ordem do discurso", uma articulação de FD que compartimenta, canalizando a produção incessante de discurso, mas é aquilo que determina a reconfiguração das FD onde se constroem os enunciados. Desta maneira, a interpelação/identificação do sujeito do discurso sofre os efeitos da contradição ideológica que inequaliza as regiões heterogêneas do interdiscurso (1983:31);

2- a determinação pela instância ideológica dos enunciados e da forma-sujeito, ou seja, conceber a instância ideológica como aquilo que determina o interdiscurso, que determina nele a circulação, os deslocamentos, os retornos, as coagulaçoes dos enunciados (ibidem), o que permite questionar a noção de Aparelhos Ideológicos de Estado entendidos como ilhotas de inscrição das práticas discursivas (e dos rituais enunciativos que as conformam) enquanto discurso autônomo de cada aparelho. Desta maneira, se desautomatiza a eficácia ideológica das práticas discursivas, já não mais amarrada a uma inscrição institucional;

3- o fato de que uma FD e sua forma-sujeito, além de se definirem como domínio de saber, incluem funcionamentos que Marandin caracteriza como modalidades enunciativas. Uma FD impóe regras intra-discursivas e modalidades enunciativas que informam o discurso de um sujeito interpelado por essa FD. Assim como o discurso não é um puro espaço de produção de sentido, do mesmo modo o individuo não é interpelado no discurso como sujeito sob a forma universal do sujeito de enunciação, mas dentro de um certo numero de lugares enunciativos que fazem que uma seqüencia discursiva seja uma arenga, um sermão, ou melhor, uma certa forma de arenga, de sermão, etc. (Marandin, 1979:41). 
4- a relevância de trabalhar a seqüência discursiva nos efeitos produzidos pela sua linearidade, i.e., trabalhar os funcionamentos enunciativos nos efeitos de sintaxe. Isto aponta para um trabalho fino de análise que leva em consideração as operações de formulação que organizam un conjunto de enunciados copossiveis em um efeito-subjetividade (Marandin, 1979:46), isto é, a organização dos lugares enunciativos no fio do discurso e as rupturas, desdobramentos, encaixes sintáticos que produzem a linearidade das formulações enquanto intradiscurso.

A questão que trazemos hoje para a reflexão é como pensar a "eficácia ideológica" (possibilidade de dizer, eficácia do dizer) de um discurso sem cair nas armadilhas de reduzi-la a um puro efeito de linguagem, no seu funcionamento genêrico-retórico-enunciativo (apagamento da história) nem descrevê-la como projeção (imediata ou mediada) de uma topografia de lugares sociais institucionalmente definidos (apagamento da língua). O conceito de lugar de enunciação, cuja delimitação inicio com este trabalho, pretende fornecer elementos para responder a essa questão. Nesse sentido, sem condições ainda de apresentar uma teorização acabada, posso apontar alguns caminhos para a reflexão.

Seguindo parcialmente Courtine \& Marandin (1983:31), definirei eficácia ideológica como um processo de repetições mais ou menos regrado - polimorfo nos discursos cotidianos, ritualizados nos discursos de aparelho - no qual as palavras são pegas na trama das reformulações: repetição sob o modo do reconhecimento dos enunciados (ou seja, o efeito de reconhecimento/identificação produzido pelo funcionamento do pré-construido sobre o sujeito de enunciação na sua atividade de formulação) e sob o modo do desconhecimento do interdiscurso (ou seja, o desconhecimento esquecimento - necessário da determinação do dizer e do sujeito pela instância ideológica). Assim, explicitar/trabalhar a eficácia ideológica de determinado corpus em análise implica descrever as operações de formulação que constituem as seqüencias discursivas como reformulações presas na rede de enunciados (domínio de saber) e na rede de lugares enunciativos (modos de dizer/modalidades enunciativas) que inscrevem o sujeito no fio do discurso (ibidem). Retomamos, dessa maneira, os funcionamentos descritos por Pêcheux (1969) como formaçoes imaginárias, porém integrados agora no quadro teórico que define a constituição do sujeito do discurso a partir 
da determinação do interdiscurso sobre os processos de interpelação/identificação ideológica que delimitam as posições de sujeito nas FD. O que implica trabalhar as diversas modalidades de identificação/interpelação do sujeito à forma-sujeito da FD na qual se constitui (Pêcheux, 1975; Indursky, 2000), não só em relação aos elementos de saber reformulados, mas também aos modos em que essa reformulação se seqüencializa, configurando diferentes lugares enunciativos.

Em um trabalho recente, Orlandi (1999a:23) afirma que $a$ ideologia funciona pelo equívoco e se estrutura sob o modo da contradição [...] não é no conteúdo que a ideologia afeta o sujeito, é na estrutura mesma pela qual o sujeito (e o sentido) funciona. A partir dessa colocação, a autora reflete sobre o funcionamento da figura da interpelação ideológica no processo de constituição do sujeito do discurso, desenvolvendo uma explicitação original desse funcionamento. Orlandi reconhece dois movimentos nesse processo:

Em um primeiro momento temos a interpelação do indivíduo em
sujeito pela Ideologia. Essa é a forma de assujeitamento que, em
qualquer época, mesmo que modulada de maneiras diferentes, è
o passo para que o individuo afetado pelo simbólico, na história,
seja sujeito, se subjetive. Ou seja se è sujeito pelo
assujeitamento à lingua, na história.[...]

Em um segundo momento teórico, o estabelecimento (e a transformação) do estatuto do sujeito corresponde ao estabelecimento (e à transformação) das formas de individualização do sujeito em relação ao Estado. Em um novo movimento em relação aos processo identitários e de subjetivação, é agora o Estado, com suas instituições e as relações materializadas pela formação social que the corresponde, que individualiza a forma sujeito histórica, produzindo diferentes efeitos nos processos de identificação. [...] Uma vez interpelado pela ideologia em sujeito, em um processo simbólico, o individuo, agora enquanto sujeito, determina-se pelo modo como, na história, terá sua forma individual(izada) concreta (p.24-25).

É justamente em relação a esse segundo movimento no processo de interpelação/identificação do sujeito do discurso que definimos os lugares de enunciação. Daí sua relação com os mecanismos institucionais de individuação/controle do sujeito e do dizer. Dessa maneira, colocamos que: 
1 - o processo de constituição do sujeito se dá pelas relações de identificação/interpelação ideológica estabelecidas com as posições de sujeito, definidas não só em relação ao domínio de saber de uma FD mas também em relação a determinados lugares de enunciação, que, por presença ou ausência, configuram um modo de dizer (sua circulação, sua legitimidade, sua organização enunciativa);

2- os lugares de enunciação devem ser considerados, dessa maneira, como uma das dimensões das posições de sujeito (constituídas nos dois movimentos descritos por Orlandi), sendo sua definição, portanto, subordinada lógica, teorica e analiticamente a esse conceito;

3- o funcionamento do silêncio afeta os processos de constituição do sentido e do sujeito(Orlandi, 1992), o que implica considerar a maneira pela qual as posições de sujeito são afetadas pelo silêncio. A interdição ou ausência de um lugar de enunciação definido em relação a uma determinada posição de sujeito pode ser explicada pelo funcionamento do silêncio sobre essa posição, produzindo o esvaziamento, a dessignificação (Orlandi, 1999b) ou mesmo a interdição dos sentidos produzidos a partir dela;

4- nesse sentido, os lugares de enunciação se definem em relação ao funcionamento do Estado e de suas instituições, porém consideradas as regras de projeção pelas quais as posições de sujeito, das quais esses lugares são parte integrante, se delimitam no interdiscurso, no processo contínuo de sedimentação das condições de produção.

\section{REFER̂ENCIAS BIBLIOGRÁFICAS}

COURTINE, J.J. Quelques problèmes théoriques et méthodologiques en analyse du discours, à propos du discours communiste adressé aux crétiens. Langages, Paris, Larousse, n. 6, 1981.

COURTINE, J.J. \& MARANDIN, J.M. Quel objet pour l'analyse du discours? In: PÊCHEUX, M. (org.). Materialités discursives. Lille: Presse Universitaire de Lille, 1983. 
GADET, F. \& HAK, T. (orgs.). Por uma Análise Automática do Discurso. Uma introdução à obra de Michel Pêcheux. Campinas: Editora da UNICAMP, 1990.

INDURSKY, F. A fragmentação do sujeito em análise do discurso. In: INDURSKY, F. \& CAMPO, M.C. (orgs.). Discurso, memória, identidade. Porto Alegre, Sagra-Luzzatto, 2000, p.70-81.

MAINGUENEAU, D. Novas tendências da Análise do Discurso. Campinas: Pontes, 1990.

MARANDIN, J.M. Problemes d'analyse du discour. Essai de description du discour français sur la Chine. Langages, Paris, Larousse, n. 55, p.17-88, 1979.

ORLANDI, E. As formas do Silêncio. No movimento dos sentidos. Campinas: Editora da UNICAMP, 1992.

ORLANDI, E. Do sentido na história e no simbólico. Escritos, Campinas, Laboratório de Estudos Urbanos, n. 4, p.17-27, 1999a.

ORLANDI, E. Maio 1968: os silêncios da memória. In: ACHARD, P. (org.). Papel da memória. Campinas: Pontes, 1999b. p.59-71.

PÊCHEUX, Michel. Análise Automática do Discurso. In: GADET, F. \& HAK, T. (orgs.). Por uma Análise Automática do Discurso. Uma introdução à obra de Michel Pêcheux. Campinas: Editora da UNICAMP, 1990. p.61-161. Original de 1969.

PÊCHEUX, Michel. Semântica e Discurso. Uma crítica à afirmação do óbvio. Trad. Eni P. de Orlandi et alii. Campinas: Editora da UNICAMP, 1988. Original de 1975.

PÊCHEUX, Michel. A Análise do discurso: três épocas. In: GADET, F. \& HAK, T. (orgs.). Por uma Análise Automática do Discurso. Uma introdução à obra de Michel Pêcheux. Campinas: Editora da UNICAMP, 1990. p.311-318. Original de 1983.

ZOPPI-FONTANA, M. Análisis lingüistico del discurso politico. E1 poder de enunciar. Buenos Aires, CEAL, 1992.

ZOPPI-FONTANA, M. Cidadãos modernos. Discurso e representação política. Campinas, Editora da UNICAMP, 1997. 